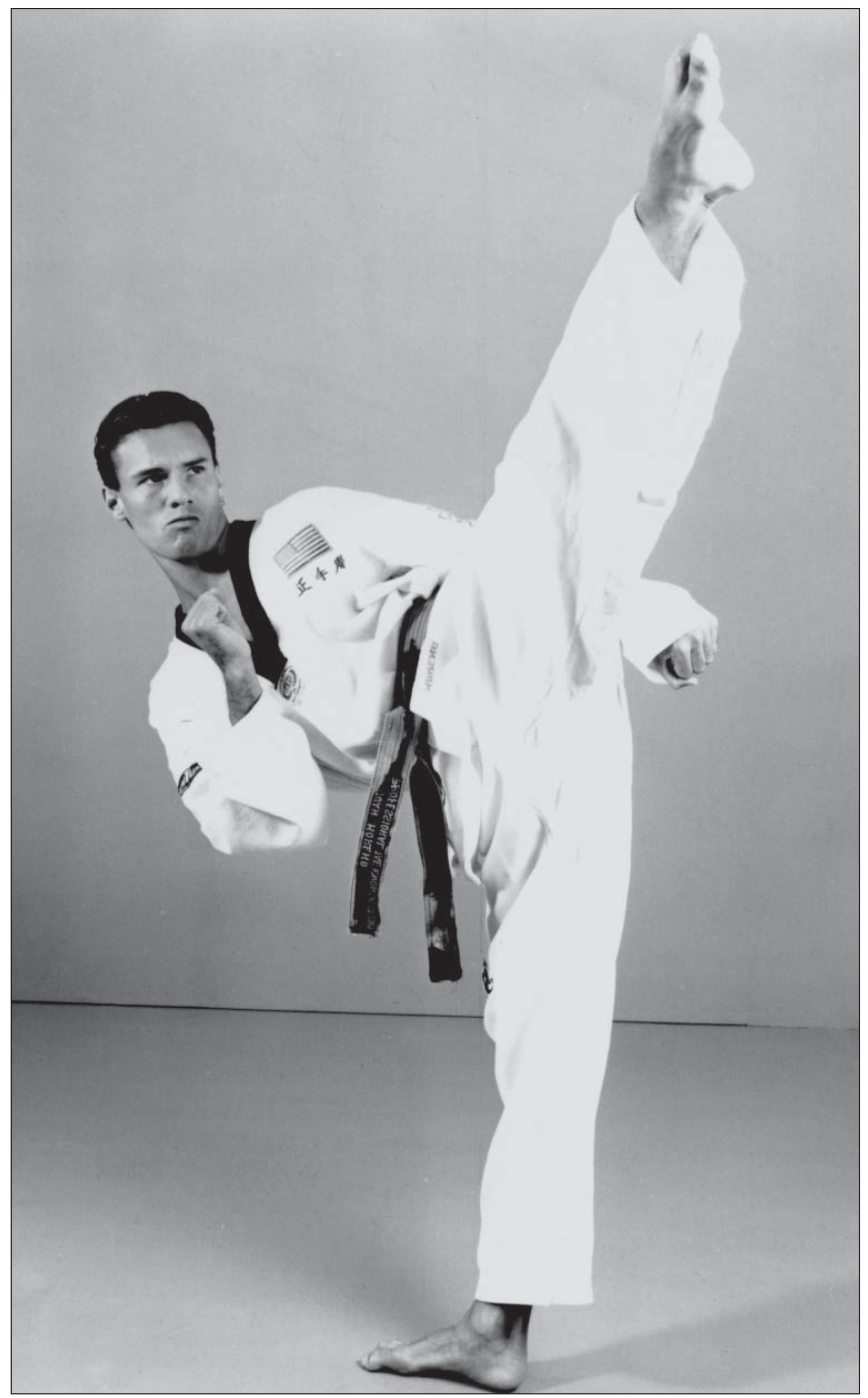




\section{El estilo de entrenamiento olímpico de Juan Moreno para atletas de Taekwondo}

\section{Entrevista por José Saporta}

\section{Introducción}

La tensión entre artistas marciales tradicionales y aquellos que practican artes marciales como deporte se remonta al menos al momento en que el Dr. Jigoro Kano desarrolló el judo desde el jujutsu y fundó el judo como deporte en 1882. Los tradicionalistas acusan a aquellos que practican los deportes marciales de haber diluido o abandonado la esencia de las artes marciales, tanto en su dimensión marcial como en su esencia como arte. Los practicantes de deportes a menudo responden a la defensiva, negando las acusaciones y argumentando que ellos son verdaderamente artistas marciales.

Juan Miguel Moreno, dos veces medallista de plata olímpico, atleta de taekwondo reconocido mundialmente, y actualmente entrenador internacional de taekwondo de primer nivel, tiene una respuesta diferente. Acepta la acusación y no se disculpa, afirmando que "No entreno artistas marciales, entreno atletas".

Esta entrevista intenta explorar y profundizar en las diferencias entre entrenar artistas marciales y entrenar atletas, según la visión del Sr. Moreno.

¿Quién es Juan Miguel Moreno? Juan Miguel Moreno, con 33 años de edad, ha sido un competidor de taekwondo reconocido mundialmente. Ganó una plaza en el equipo olímpico estadounidense de taekwondo durante tres Juegos Olímpicos y ha ganado en dos ocasiones la medalla de plata olímpica. Vivió y entrenó durante seis años en el US Olympic Training Center [Centro de Entrenamiento Olímpico de los EE.UU.]. Su larga lista de medallas en competiciones internacionales incluye también una medalla de oro en los Juegos Panamericanos de 1991 en la Habana, Cuba, y una medalla de oro en la Copa del Mundo del 2000 en Lyon, Francia. Fue nombrado dos veces competidor del año por la revista Black Belt.

Actualmente el Sr. Moreno es el entrenador del Team Miami, un equipo de atletas de élite de taekwondo que compiten nacional e internacionalmente. Es un entrenador de taekwondo conocido a nivel mundial y ha dirigido seminarios de combate y entrenamiento a lo largo de los Estados Unidos. Finalmente, y quizás lo más importante, fue una de las cinco personas seleccionadas por el Comité Olímpico de los Estados Unidos (USOC) para el Governance and Management Committee of the US Taekwondo Union (USTU) [Comité de Gobierno y Asesoramiento de la Unión de Taekwondo de los EE.UU.] cuando estaba en activo. En este puesto se dedicó a reestructurar el taekwondo olímpico de los Estados Unidos y a mejorar los programas para identificar y desarrollar a los jóvenes y prometedores atletas de taekwondo. Junto con Jean Lopez, Moreno es actualmente uno de los dos entrenadores del equipo nacional de Taekwondo de los EE.UU. designados por el Comité Olímpico estadounidense.

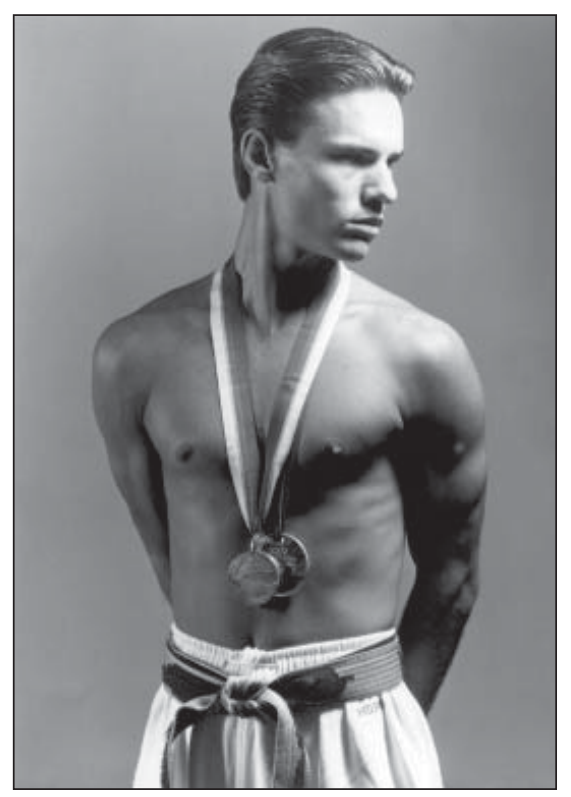

(Arriba y página anterior) Con su participación en tres Olimpiadas y un sobresaliente historial en competiciones nacionales, Juan Moreno se retiró en el año 2000.

Todas las fotografías son cortesía de J. Saporta, excepto las que figuran en esta página y en la anterior que son cortesía de Juan Moreno. 


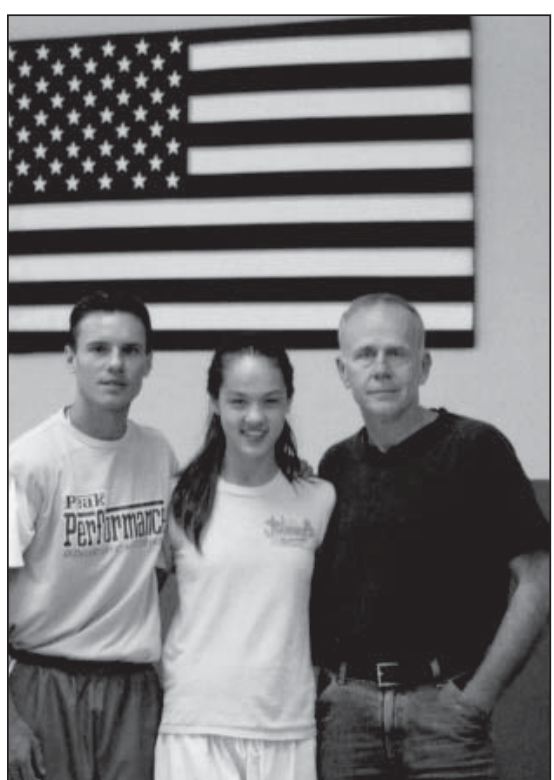

De izquierda a derecha: Juan Moreno, Sondra Saporta (hija del autor y dos veces medalla de oro en las olimpiadas nacionales) y el autor.

\section{Entrenando en el gimnasio de Juan Moreno}

Los lectores que entrenen en lugares tradicionales pueden encontrar difícil imaginar el entrenamiento en el gimnasio del Sr. Moreno. La atmósfera refleja la diferencia entre entrenar atletas y entrenar a artistas marciales. El rango de edad de los atletas va desde jóvenes adolescentes hasta los veinticinco años. Visten pantalones sudados, camisetas, camisetas sin mangas, y pueden ir descalzos o vestir zapatillas de taekwondo. El objeto más parecido al uniforme tradicional que puedes ver son los pantalones y la camiseta sin mangas o la camiseta. No hay cinturones u otra forma de distinguir el rango o la antigüedad. Sólo eres juzgado por lo duro que entrenes. No es una cuestión de linaje, rango, o incluso habilidad, pero sí de esfuerzo. Da el 100\% y serás aceptado en este grupo intensamente unido. Cuando no entrenan, el grupo suele socializarse o van juntos al cine.

El observador de la sesión de entrenamiento del Team Miami no puede ayudar, pero sí ser subyugado por la energía y la intensidad. El fuerte impulso de la música fomenta la intensidad de los atletas. No hay aire acondicionado, sólo un ventilador para aliviar el calor de Miami. Empapados en sudor, avanzan en filas para practicar rápidos esquemas de juego de piernas. La primera fila avanza, moviendo rápidamente un hombro para amagar un ataque y retirarse, cambiando los pies, y a continuación desplazándose adelante mientras gritan, “¡Paaaho!”. El grito se eleva por encima de la música. La siguiente fila se adelanta y repite lo mismo. Los atletas trabajan por parejas; una pareja sigue a otra yendo hacia el fondo. Un miembro de la pareja ejecuta rápidas combinaciones de trabajo de pies, cambios y giros, y el otro intenta hacer de espejo de su compañero o compañera, acabando al fondo con un intenso grito. Los atletas aprenden a controlar el enfrentamiento variando el ritmo y el tempo: rápidos y bruscos movimientos para poner al oponente al límite, movimientos lentos y rítmicos para hacerse confiar al oponente, o movimientos de avance, agresivos e insistentes, para dibujar un ataque y preparase para la contra. Hay ejercicios con paletas, ejercicios con el hogu (protector pectoral), ejercicios de situación y ejercicios de lucha. Uno lanza una patada mientras el otro se desplaza o gira fuera de su dirección (se puede ver que aquí no hay bloqueos) mientras simultáneamente se contran y gritan "¡Paaaho!", y el primer atacante evade y contra el contraataque. Cuando es hora de cambiar de compañeros, los atletas estrechan sus manos sin saludarse mediante una inclinación. Como observador, con la música, el grupo gritando al unísono, la velocidad, la implacable energía e intensidad, hace que te encuentres sentado al borde de la silla intentando contenerte para no saltar y correr alrededor para descargar la energía.

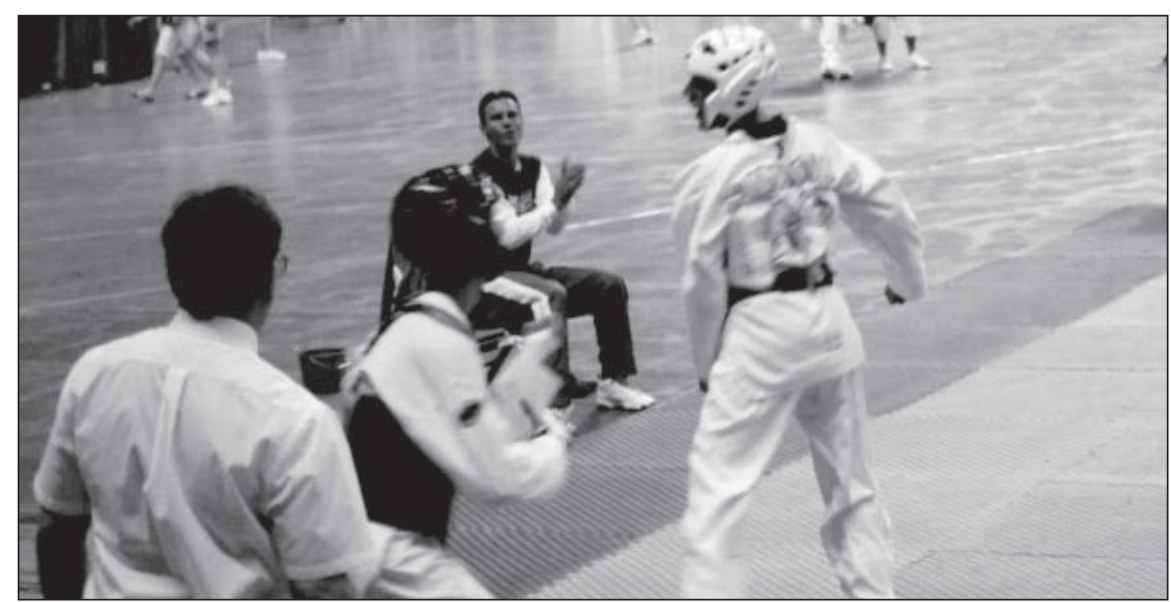


Esta entrevista tuvo lugar el 3 de octubre de 2004 en Miami, Florida, donde el autor asistió a un seminario de entrenamiento dirigido por el Sr.

\section{Entrevista}

José Saporta (JS): ¿Cuáles son sus antecedentes en las artes marciales? Juan Miguel Moreno (JMM): Empecé en el estilo ITF de taekwondo (Federación Internacional de Taekwondo, fundada por Choi Hong $\mathrm{Hi}$ ). Mi maestro se llamaba Gerald Cook, y estaba en las afueras de Chicago. Él tuvo un maestro coreano muy tradicional que también había sido muy importante en el judo de los EE.UU. Eran serios artistas marciales tradicionales. Trabajaban de lunes a viernes los bloqueos, de arriba hacia abajo, posiciones, tratando de corregir todo, para hacer nuestras técnicas perfectas. Existía poco énfasis en el combate; éramos afortunados si luchábamos una vez a la semana, los sábados, puede que durante una hora. Todo estaba engranado para aprender los fundamentos de las artes marciales, la disciplina, la defensa personal, las viejas cosas tradicionales.

JS: ¿Hubo un momento en su desarrollo cuando cambió de verse como artista marcial a verse como un atleta?

JMM: Nosotros no entrenábamos para competir, entrenábamos de forma tradicional, pero, con el tiempo, el ir a las competiciones llegó a ser más un punto central para el grupo. Cuando tienes once años no piensas en las artes marciales tradicionales. Sencillamente piensas en qué es lo más divertido. Para mí intentar competir era una cosa divertida, vigorosa y desafiante.
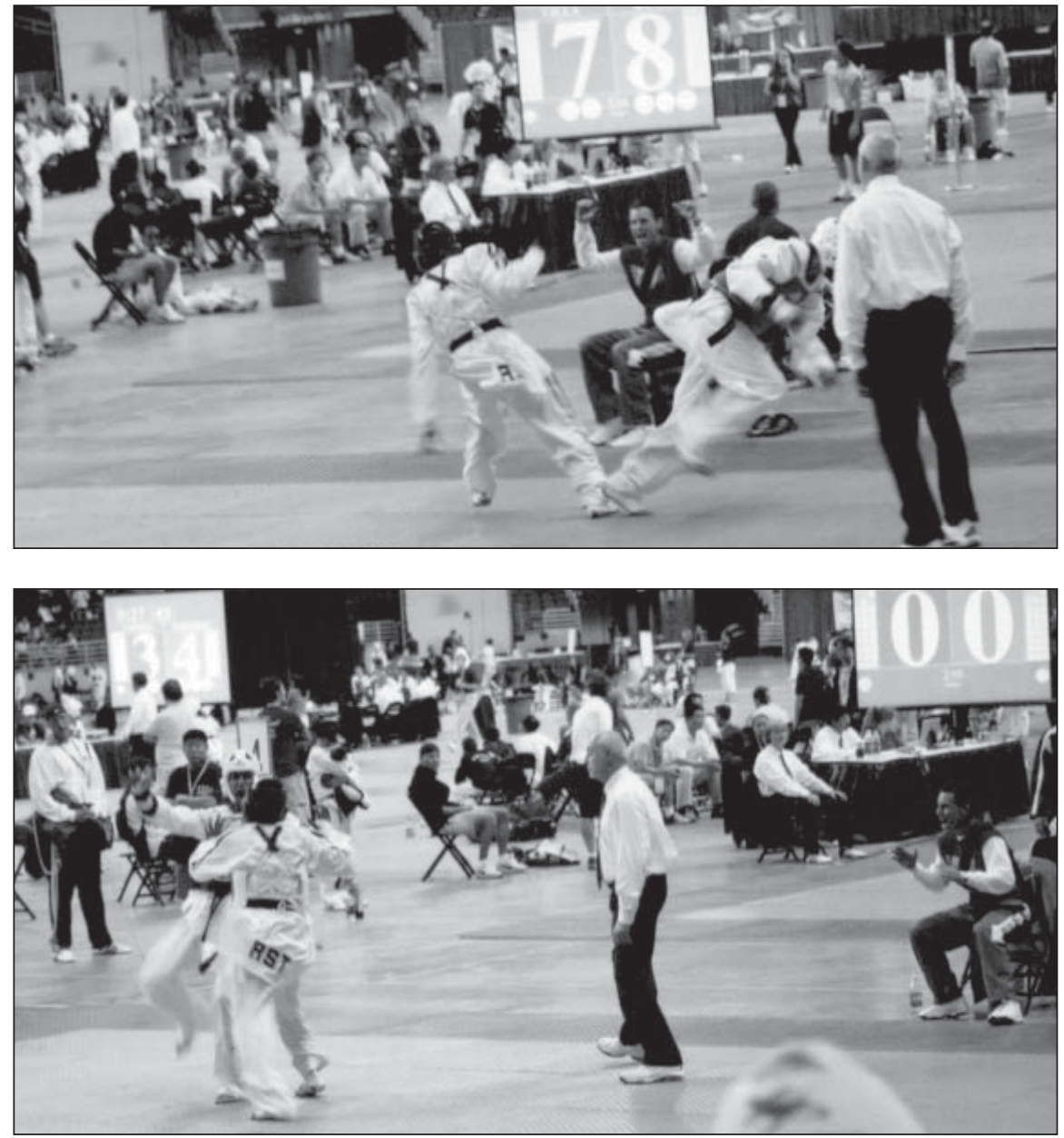
Con el tiempo cambié a torneos de kickboxing y de kárate. Pronto estaba compitiendo a un alto nivel en el circuito de kárate deportivo. En ese punto me veía como un artista marcial deportivo, pero no tenía idea del hecho olímpico. Entonces, en 1986, oí sobre la presencia del deporte en las Olimpiadas. Al año siguiente tenía quince años. Fui a Corea a entrenar en una de las más prestigiosas universidades de artes marciales, la universidad Kyung Hee. Vieron que era demasiado joven y demasiado pequeño, por lo que me enviaron a una escuela secundaria (Escuela Secundaria Dong Sung), la cual tenía el equipo de taekwondo número uno de Corea. Su entrenador llegó a ser entrenador olímpico en 1988 y en 2004. Vi cómo practicaban esos chicos y cómo eran de buenos. Esto cambió por completo mi forma de pensar. Tenía que llevar mi entrenamiento totalmente a una nueva cota para competir a ese nivel. Fue entonces cuando pensé, "puedo hacer esto, ahora soy un atleta y quiero hacer esto a nivel olímpico".

JS: Quiero explorar con usted lo que esto significa, pero primero, ¿Qué está haciendo ahora y qué tipo de gente entrena?

JMM: Después de las Olimpiadas del 2000 me retiré de la competición. Había decidido abrir una escuela comercial de artes marciales, pero lo que realmente quería hacer y me apasionaba era entrenar e intentar ayudar a mejorar a los atletas. Actualmente tengo un gimnasio donde todo lo que hago es entrenar a personas que quieren llegar a ser miembros del equipo nacional, ya sea el equipo nacional júnior, el equipo nacional sénior o el equipo nacional universitario. Sólo recibo a cinturones negros o justo el rango más alto antes de dicho cinturón. Generalmente han practicado artes marciales durante un mínimo de tres o cuatro años y ya han pasado por los distintos grados. No están interesados en progresar al siguiente nivel y conseguir su primer, tercer o cuarto grado. Sólo quieren ganar medallas de oro.

\section{JS: ¿Nivel de atletas de élite?}

En un seminario reciente, Moreno comparte consejos sobre la dinámica de las patadas.

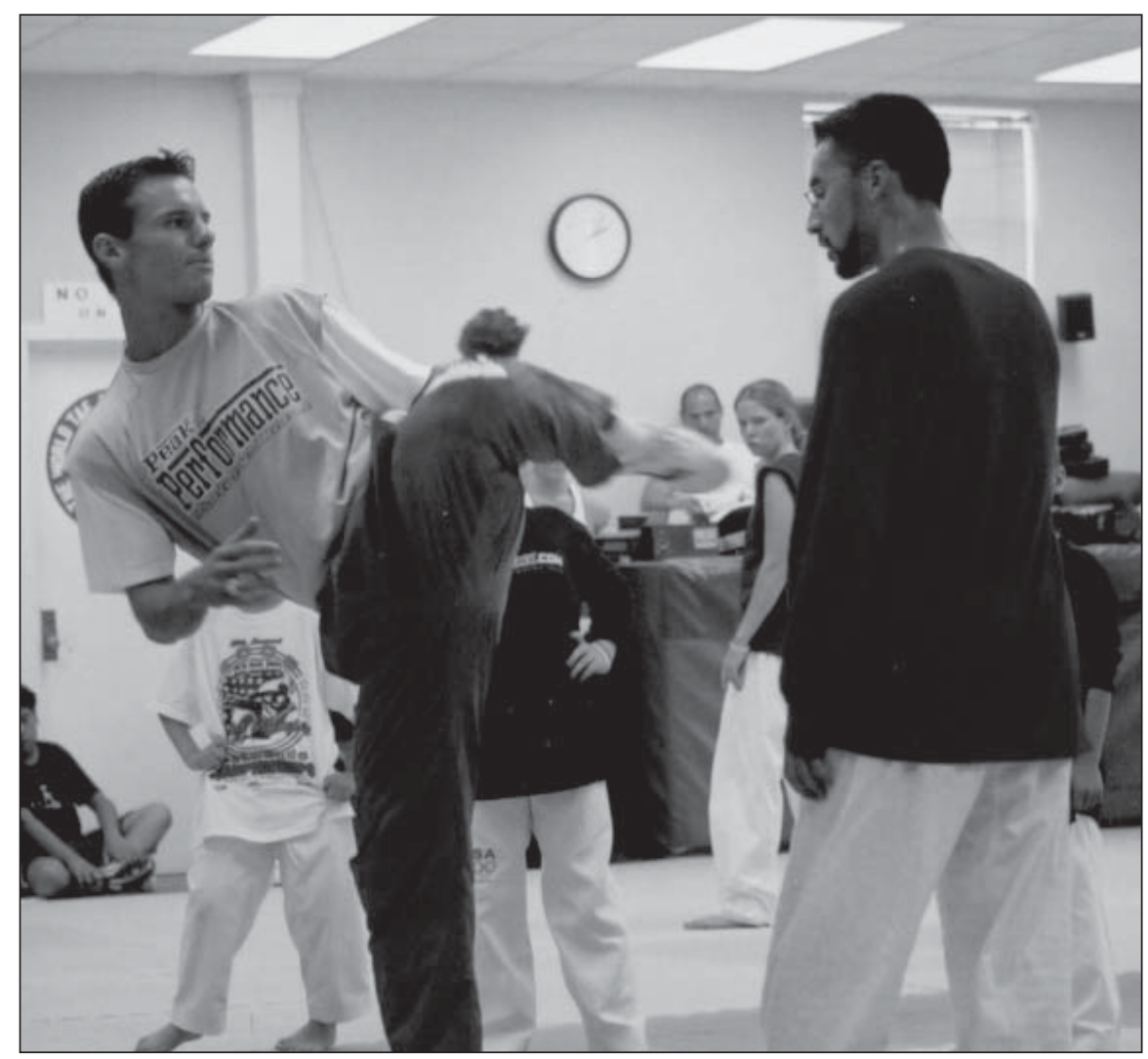


JMM: No todo el mundo es un "atleta de elite". Pero hay personas que tienen el potencial para ser de élite, prometen llegar a un nivel de élite. Yo tengo un número cumplido de competidores de élite a nivel mundial. A menudo tenemos equipos nacionales de otros países que vienen a entrenar con nosotros durante periodos de tiempo variables.

JS: ¿También está trabajando con la USTU, el cuerpo nacional que regula el taekwondo, y en el desarrollo del atleta?

JMM: Desde el 2000 he estado en varios equipos de entrenadores. Ahora, el Comité Olímpico de los EE.UU. básicamente se encargó de la Unión de Taekwondo de los EE.UU., y designó a cinco personas para el comité de dirección y gobierno. Soy una de esas cinco personas, la única persona de taekwondo. Los otros miembros son el anterior director de esquí acuático de los EE.UU., que es un gurú en gobernación y en estatutos, el Director Ejecutivo de la lucha libre de los EE.UU., otro deporte de combate y uno de los mejores programas del mundo, el anterior Director Ejecutivo del triatlón de los EE.UU., quien tomó un deporte minoritario en este país y lo convirtió en un deporte grande, y un auditor de la USOC. Nosotros fuimos seleccionados para volver a desarrollar y reestructurar nuestro deporte. Debido a mi posición aquí he podido ayudar a reestructurar el taekwondo de abajo a arriba, y también a estructurar el desarrollo del atleta. Un programa júnior que estamos intentado llevar a cabo es tener un programa firmemente arraigado para primero identificar y después desarrollar a las personas, sin esperar simplemente a que lleguen a ser campeones nacionales o esperar a que lleguen a ganar medallas olímpicas. Hay personas como yo, Herb Perez, o Arlene Lima que hemos llegado a ser medallistas olímpicos, pero no porque la organización nos desarrollara. Queremos y necesitamos cambiar lo que nos rodea, identificar a esos chicos, ejecutar programas para desarrollarlos desde una edad temprana, y así, cuando tengan quince o dieciséis años, estarán listos para ganar los campeonatos mundiales. No es diferente a la gimnasia, la lucha libre o el fútbol. El resto de deportes hacen esto, no sólo en los

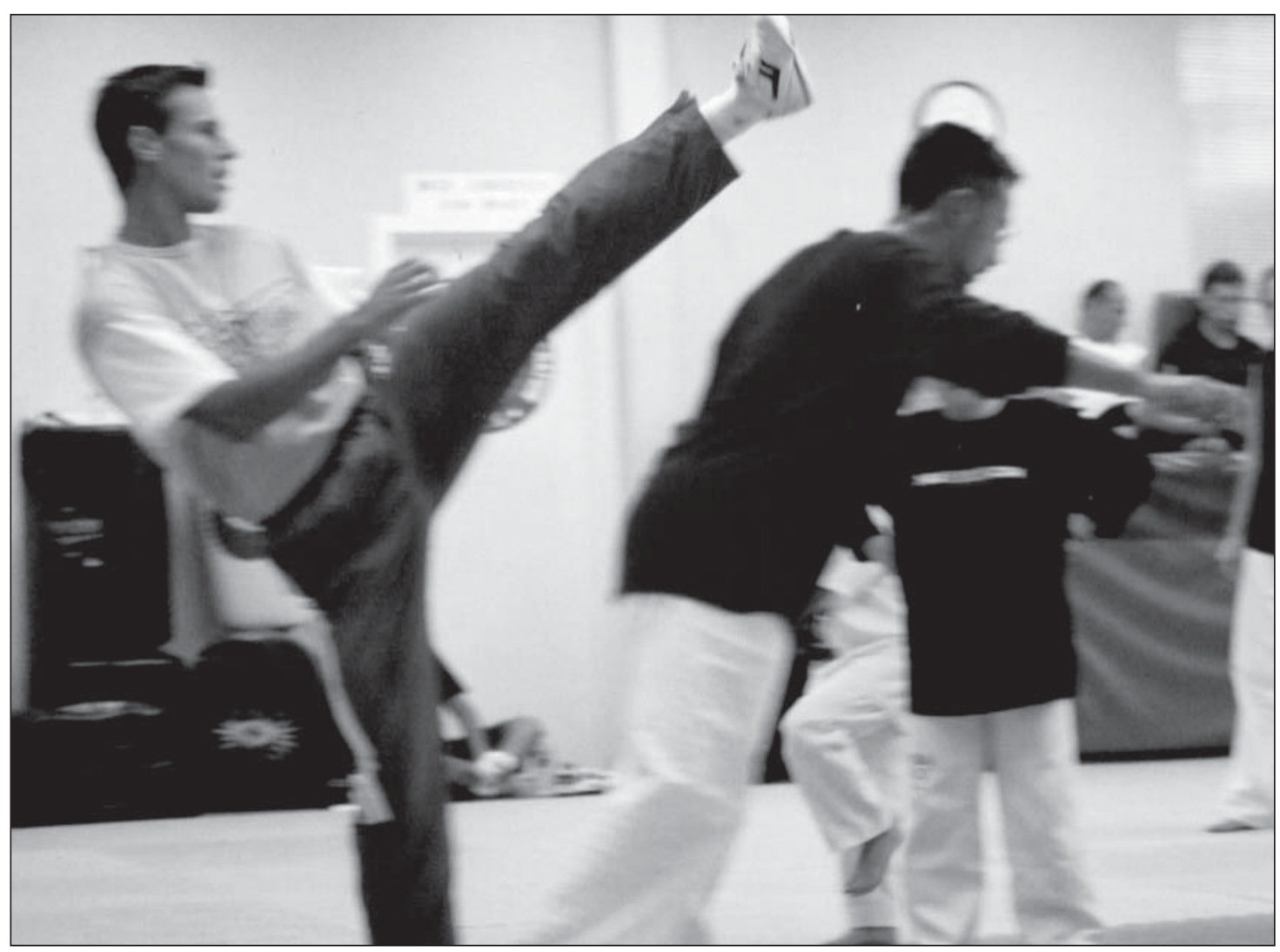


Estados Unidos sino en todo el mundo. En Estados Unidos, en el taekwondo, no lo teníamos.

JS: Me dijo una vez que las artes marciales son magníficas, pero que usted no entrena artistas marciales. Entrena atletas. ¿Qué quiere decir acerca de eso?

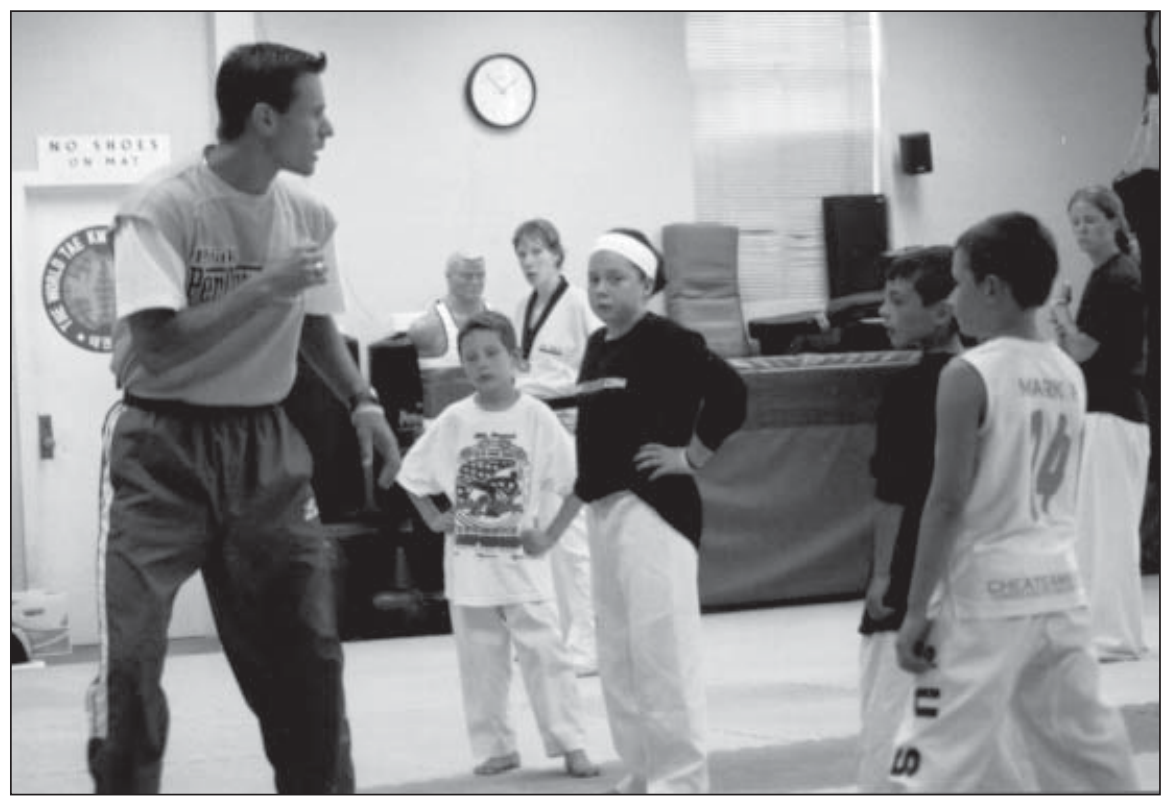

JMM: Es un punto polémico. Pero incluso yo mismo, a estas alturas de mi vida, no me considero un artista marcial.Meconsiderounentrenador, un entrenador deportivo. ¿Tengo experiencias en las artes marciales? Sí. ¿Tengo cualidades que pueden ayudarme y que provienen de las artes marciales? Absolutamente. Pero la gente que tengo no está interesada en las artes marciales o en practicar defensa personal. Las artes marciales son defensa personal, ya sea esgrima, lucha libre, o boxeo, es el arte de la autodefensa. El taekwondo deportivo no es defensa personal, es un deporte. Es un deporte de combate, así que supongo que puedes caracterizarlo como arte marcial. Pero las personas que lo están practicando en estos momentos no son artistas marciales.

Ya deseen ser un atleta olímpico o participar simplemente como entretenimiento, muchos niños practican taekwondo. Independientemente de esto, Moreno es una buena influencia y un excelente modelo para imitar.
Los tipos que están en la cima mundial, podría decir que probablemente muchos de ellos no sabrían defenderse en la calle. Muchos de ellos no pueden enseñarte una forma. Muchos de ellos probablemente no podrían enseñar a alguien cómo defenderse. Sólo porque den buenas patadas, anoten puntos y ganen competiciones no significa que sean capaces de defenderse. Las personas con las que trabajo no anhelan aprender a defenderse o perfeccionar una forma. De hecho, un montón de gente del taekwondo deportivo tiene, en un curioso sentido, una mala técnica tradicional, cuando realizan las patadas laterales, o las posiciones con las manos de canto o bloqueos, cosas como esas. Porque esas cosas no son aplicables a la cara deportiva del taekwondo. No son verdaderos artistas marciales; más bien ellos son deportistas. Ahora, estoy dispuesto a apostar que con un poco de cambio aquí o allí ellos podrían llegar a ser buenos artistas marciales, fuertes y sólidos, en la autodefensa o en cualquier cosa que decidieran. Pero ellos han desarrollado su cuerpo y su mente para el deporte.

JS: Entremos en las diferencias del proceso de entrenamiento de los artistas marciales frente al entrenamiento de atletas. ¿Qué echa de menos del entrenamiento de las artes marciales tradicionales que exigiría para entrenar al atleta de artes marcial moderno?

JMM: La ciencia. Las artes marciales tradicionales se enfocan simplemente en hacer técnicas, bloqueos y patadas y golpeos. Esto es bueno, puedes lograr ser rápido y fuerte haciendo esto. Pero no es el camino óptimo de conseguir ser fuerte y rápido. Los artistas marciales tradicionales se siguen basando en conceptos de hace quince, treinta, cincuenta, incluso cientos de años, que sencillamente están anticuados. Hay otras técnicas, físicas, psicológicas, conceptos que puedes llevar a cabo para hacer de los atletas mejores atletas.

JS: ¿Son métodos de entrenamiento más abiertos y enfocados estratégicamente, y menos condicionados por la tradición? 
JMM: Sí. Por ejemplo, tengo tres programas diferentes para mis atletas. Un programa de carrera, un programa de fuerza y acondicionamiento, y un programa específico de taekwondo deportivo. Por tener tres programas diferentes llegarás a ser un mejor atleta. El programa deportivo específico es donde trabajas tus patadas, tu estrategia, los ejercicios de combate, ejercicios con paleta, ejercicios con el hogu, ejercicios de situación, tu habilidad técnica, la dirección del juego... cosas como esas. Pero, simplemente hacer taekwondo no es suficiente. Debemos fortalecer nuestros músculos a través del entrenamiento de resistencia, de pesas o con gomas elásticas, conseguir velocidad y explosividad con el entrenamiento pliométrico y de velocidad, poner a tono tus músculos para que puedan responder a tu voluntad, a tus órdenes, y en el momento oportuno. No te volverás una mejor "persona de taekwondo", pero serás un mejor atleta de taekwondo.

La mayoría de estas cosas tienen lugar fuera del gimnasio de taekwondo, fuera del ring. Si sólo hubiera hecho taekwondo, podría haber sido bastante bueno. Puede haber alguien por ahí fuera que gane así. Pero el 95\% de la gente necesita de estos otros programas específicos. Incluso de la nutrición, yendo a un nutricionista profesional, calculando qué comidas pueden darte el rendimiento óptimo o ayudarte en la recuperación, o ayudarte a responder y a incrementar las ganancias. Es mucha la necesidad de dirección. No sólo es ir al gimnasio y dar patadas durante dos horas. Es planear tu día entero. Todo lo que se hace es científico, para tener una actuación óptima, la máxima actuación. Simplemente mejorar en el arte no es suficiente, en esta época, para ser el mejor atleta. Esa es una de las cosas más difíciles que tengo que conseguir de mis atletas, que no sólo que lo entiendan sino que también lo pongan en práctica. Puedes ser muy bueno en taekwondo, ¿Podrías imaginar si realmente hubieras hecho la carrera que te pedí, o podrías imaginar si te pusiera en un programa de fuerza? ¿Podrías imaginar si comieras adecuadamente? ¿Podrías imaginar si fueras a un psicólogo deportivo? Ir al gimnasio y entrenar ocho horas diarias no es suficiente. No es suficiente estrategia. Es aquí donde se ve la diferencia entre un atleta y un artista marcial. Un artista marcial irá únicamente al dojang (sala de práctica) y practicará religiosamente. Un atleta dice: necesito correr, necesito saltar, necesito comer, necesito visualizar, necesito pensar. Necesito todas estas cosas.

\section{JS: ¿Hay métodos del entrenamiento} físico de las artes marciales tradicionales que utilice en el entrenamiento de los atletas marciales?

JMM: Yo diría, los ejercicios calisténicos y las cosas de salud que hicimos, no. Las posiciones y las habilidades técnicas que aprendimos, no. Probablemente la única cosa que yo uso son los aspectos mentales. Nada del aspecto físico.

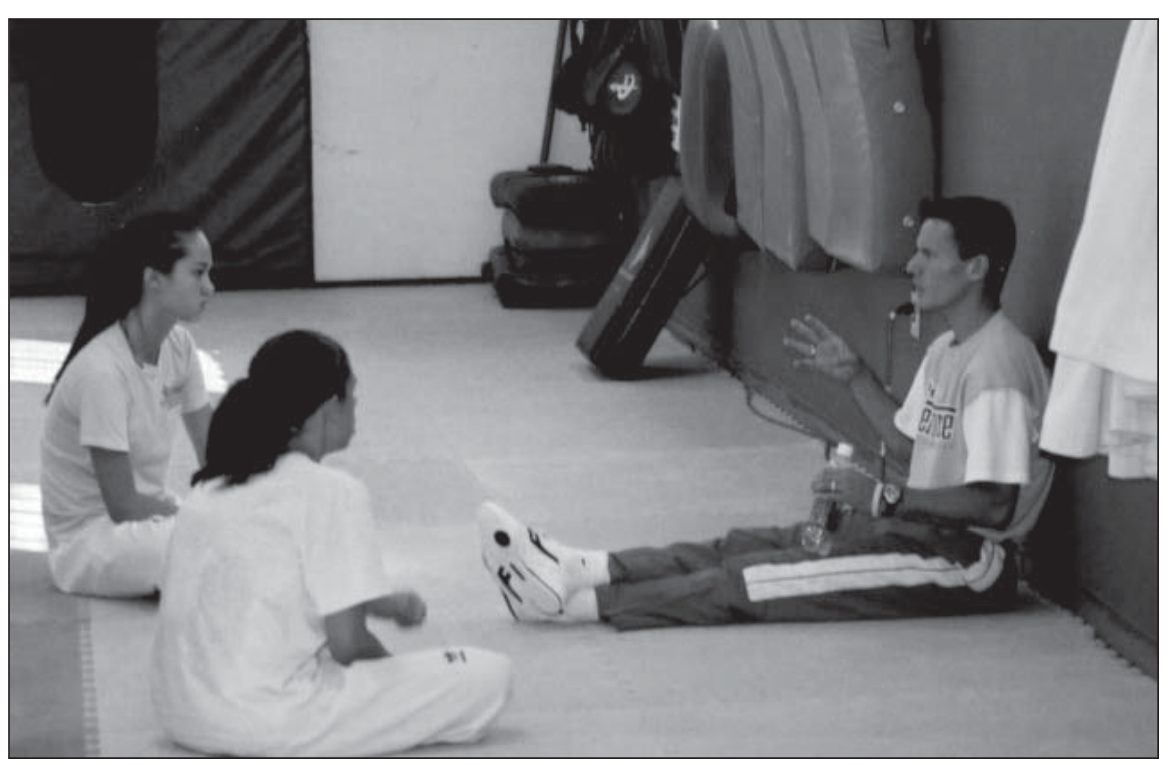

JS: ¿Su entrenamiento en las artes marciales tradicionales, los bloqueos, las posiciones, etc, jugaron algún papel en su éxito como atleta de taekwondo? JMM: Por un lado puedo decir que no, porque las habilidades que yo llevo a cabo hoy día no se parecen a ninguna de esas técnicas. Por otro lado digo que sí, porque tuve que ser muy disciplinado para perfeccionar apropiadamente la posición, la patada, el bloqueo tal como me los enseñaron entonces. 
Practicando las formas día tras día, durante horas, perfeccionando la patada lateral, los bloqueos, las posiciones. Nunca se terminaba. Siempre tenía espacio para la mejora y yo nunca estaba satisfecho. Ahora puedo discrepar sobre la posición apropiada o sobre la manera de dar patadas debido al desarrollo del deporte. El proceso era probablemente más influyente que las propias habilidades o técnicas. Lo que me ayudó en mi carrera atlética fue el compromiso con la perfección que aprendí a través del entrenamiento tradicional.

\section{JS: ¿Acerca de las diferencias en la actitud entre entrenarse como artista marcial y entrenarse como un atleta, o en desarrollo mental, o cómo se ve usted mismo?}

JMM: Tengo un montón de respeto por las artes marciales tradicionales y tengo pasión por el atleta. Creo que el atleta es, en un sentido, un poco una meta a corto plazo o estrecha de miras. Buscan el ahora. Buscan a dos o tres años. Todo es para la próxima competición y para llegar al nivel olímpico. El escaparate de las oportunidades para un atleta es muy pequeño. Puedes tener tres o cuatro años, o cinco años si tienes suerte. Para un artista marcial la vida es larga sin un punto final. Creo lo que me has dicho, es el proceso por encima de la meta. Esa es una parte pura de las artes marciales que yo realmente, realmente admiro. Realizar algo saludable sólo con el objetivo de hacerlo, no porque haya alguna meta. No porque haya una medalla de oro o un torneo que ganar, simplemente por la pasión y el encanto. Ambos, el atleta y el artista marcial, tienen que tener disciplina y compromiso, pero el marco temporal es muy diferente. Podría decirse que el lado deportivo es la filosofía occidental, y el lado de las artes marciales es la filosofía asiática. No voy a decir que una sea correcta o equivocada. En eso es donde está el problema con el artista marcial tradicional. Ellos sólo dicen no, no, no, ese camino es malo. Ese camino es equivocado. La mayoría querría aferrarse a la tradición. Dicen: "ustedes tienen una corta visión”. Y porque tienes una visión a corto plazo estás equivocado. Yo no estoy de acuerdo con eso.

Aquí y en la página siguiente, puede apreciarse que la práctica intensa es una parte importante de los seminarios de Moreno.

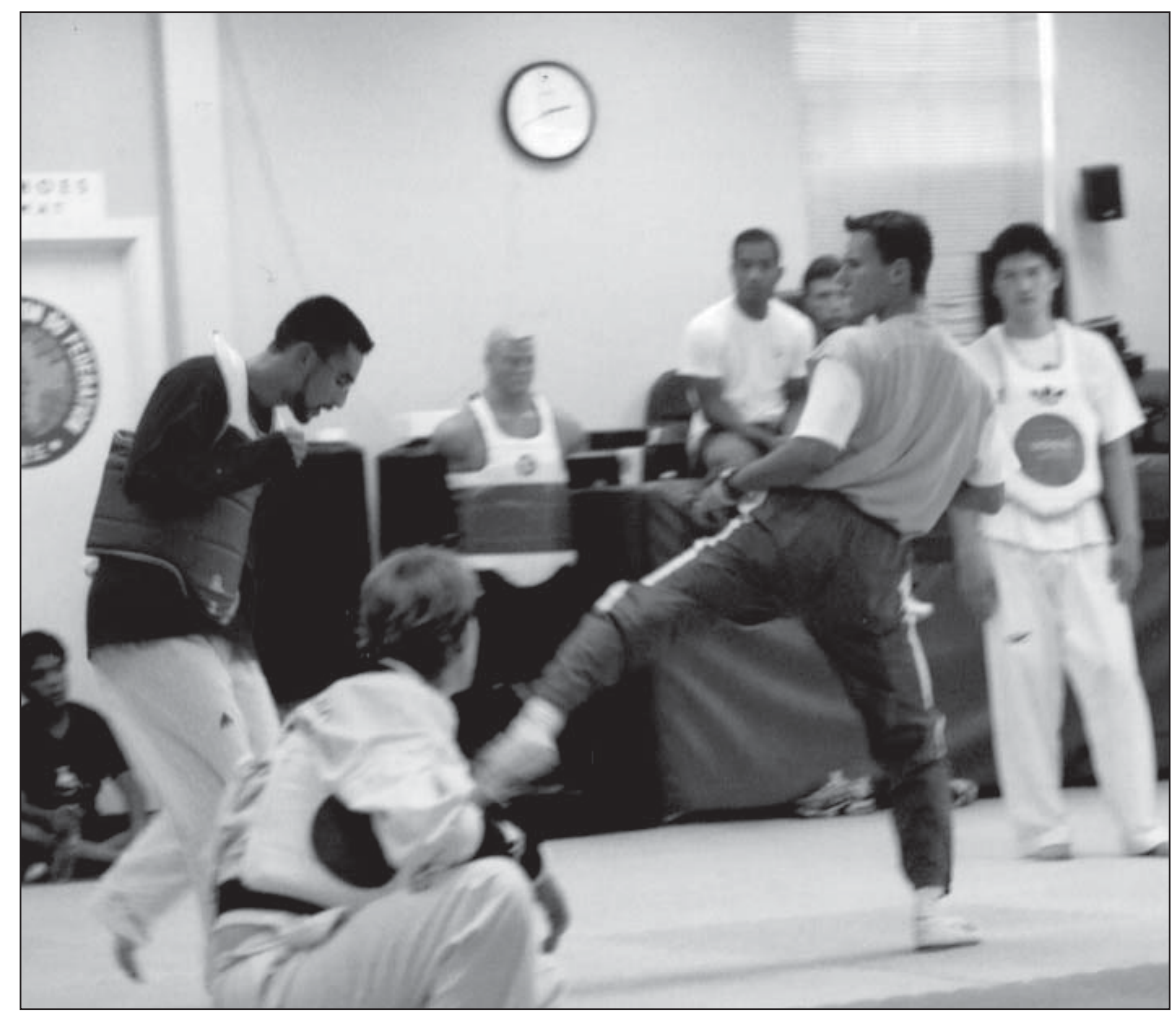


JS: ¿Hay algunos aspectos del entrenamiento mental de las artes marciales tradicionales que apliques en el entrenamiento de tus atletas?

JMM: No en términos de técnicas mentales. Porque incluso entonces, no pienso que los instructores fueran tan intuitivos que realmente tuvieran maneras psicológicas de ayudarte a llegar a ser mejor o más fuerte. Era más bien el ambiente mental general. Más la filosofía o la disciplina interna y de auto respeto. Teniendo respeto por el instructor, que era tu líder, tu mentor, y al que ibas a ver y a seguir. Intentarías ser como ellos. Quiero decir que, cuando crecí, el instructor de artes marciales era, sé que esto es menos hoy en día, pero ellos eran casi como dioses. Eran casi míticos. Harías lo que fuera por ser tan bueno como ellos. Porque en esa época, estas eran personas que llevaban veinte y treinta años entrenando en el arte. Conocías lo por que habían pasado, y las tradiciones que habían vivido y cómo era el aprendizaje. Envidiabas aquello. Tú querías eso. Hoy en día tienes instructores que han estado practicando durante tres y cuatro años y están enseñando en escuelas comerciales.

JS: Un tipo de modelo y una disposición mental, pero no técnicas específicas. JMM: No técnicas específicas. Pero sí un modelo y una disposición mental. Quieres el duro trabajo ético de las escuelas antiguas. Quieres la disciplina de las escuelas antiguas. Quieres el respeto de las escuelas antiguas. Respeto para los profesores y los estudiantes más experimentados. Intento retomar esa mentalidad para mis atletas.

JS: Es importante para la gente el tener a alguien a quién idealizar, para parecerse. Pero no tenemos mucho de eso en nuestra cultura.

JMM: Absolutamente. En las artes marciales sí puedes. Pero entonces es muy desolador cuando el artista marcial te decepciona.

\section{JS: ¿Hay pérdidas en el entrenamiento como atleta en relación al entrenamiento como artista marcial?}

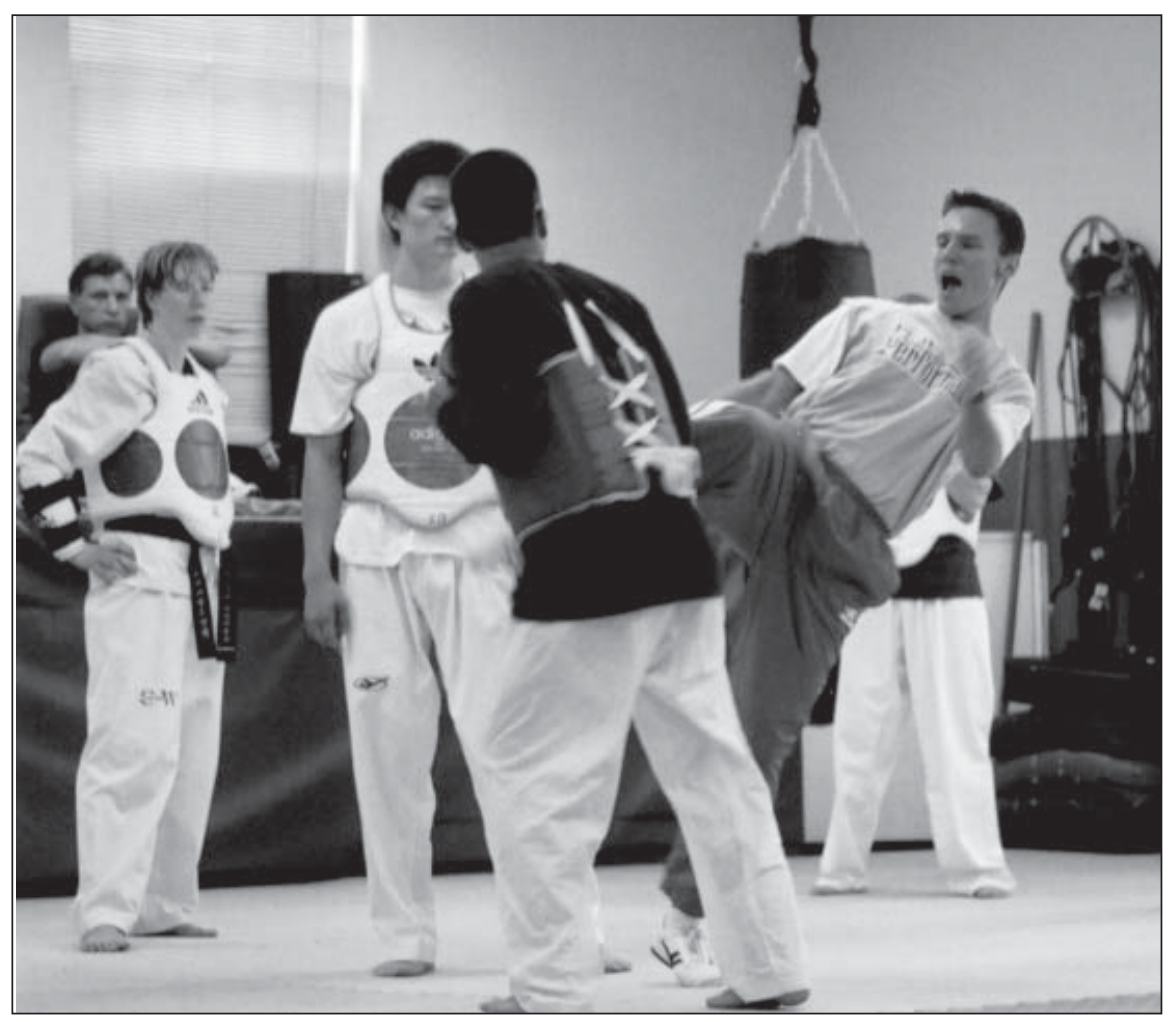


JMM: Muchas cosas se pierden. Los artistas marciales tradicionales son buena gente, con sólidos fundamentos. Tienen una buena moral, una buena ética, buenos valores familiares, y son conscientes de la cultura y la sociedad. Mientras que en el caso de los atletas, en el periodo actual, esto no es tan cierto. Por eso se ven casos de doping, porque sólo quieren ser mejores, más rápidos, y ganar la medalla de oro a toda costa. Puedes ver las trampas todos los días en los deportes. Verás, odio decirlo, pero es un tipo con una mentalidad asesina, como para pisar a alguien y hacer cualquier cosa para conseguir el nivel más alto. No sólo sucede a los atletas, sino también a los padres y a los entrenadores. Pienso que se estropea la fibra de sociedad. No es una cosa técnica. Es una cosa moral o ética.

La excepción a esto es que en el pasado las cosas no siempre eran mejores. No todos los artistas marciales tradicionales eran tan santos y tan puros. Muchos de ellos eran y son corruptos, mucho eran egoístas, y muchos de ellos han hecho cosas dañinas a las personas. Muchos simplemente tomaban, tomaban, tomaban y no necesariamente daban. Tengo algunos amigos íntimos unos años mayores que yo y que crecieron en una escuela asiática. Eran prácticamente esclavos o sirvientes. ¿El abuso físico que recibieron era para su mejora? ¿Era un tiempo mejor, se suponía que aprendías mejor, cuando el maestro o los grandes maestros podían pegarte con un palo y partírtelo en la cara? ¿Ese era el mejor aprendizaje? Creo que no. Puede compararse en cierta manera al trato que los hombres daban a sus esposas en el pasado, cuando este comportamiento era aceptado.

\section{JS: Usted respeta las artes marciales tradicionales pero es crítico con algunos maestros tradicionales.}

JMM: Tengo un gran respeto por ello. En algún punto estoy de vuelta de ser un artista marcial. No digo que de una manera simplista o una manera negativa. Pero muchos, yo uso ligeramente este término, "maestros", lo usan en el antiguo sentido mítico en que son míticos en sus destrezas y en su habilidad, en sus enseñanzas. Creo que están equivocados y que es un perjuicio para las personas. Utilizan humo y espejos tal vez por una carencia en su educación o en sus propias habilidades. No quiero ser injusto, hay algunos asombrosos, y ahora utilizo esta palabra en su sentido fuerte, "maestros" por ahí fuera. Apenas creo lo que pueden hacer con sus cuerpos y con sus mentes. Esas son personas especiales que trabajan muy, muy duro. No es que tengan una buena formación científica. Sencillamente son personas únicas. Pero soy crítico cuando no son abiertos y no se desarrollan del mismo modo que les piden a sus alumnos que se desarrollen. Se aferran a la tradición de una manera cerrada.

JS: Algo de eso es cultural. Algunas culturas tienen más respeto por la tradición mientras que la cultura americana aprecia la independencia.

JMM: Yo entiendo que la mentalidad asiática se opone a la mentalidad occidental. Nosotros tenemos ahora mismo un problema dentro de nuestro deporte en la lealtad frente a la meritocracia. Lo importante es qué puedes hacer ahora mismo por el programa, no importa si eres joven o viejo, o quién es tu maestro. Mientras que en la tradición asiática, si eres mi estudiante joven o veterano, cuidaré de tí, te encontraré un lugar. Te delegas en la autoridad del veterano o del maestro. Ese ha sido un perjuicio para nuestros programas. Así que sí, algo de esto es cultural.

JS: ¿Recomienda que un niño o adolescente se inicie en un arte marcial tradicional en lugar de entrenarse como un atleta?

JMM: Absolutamente. Probablemente a la mayoría de personas que conozco. Debido a mi amor y admiración por las artes marciales. Porque las artes marciales probablemente pueden hacer más por usted de lo que puede hacer el ser un practicante de taekwondo deportivo. El ser atleta no es para todo 
el mundo. No todos están dotados física y mentalmente. El marco para las oportunidades es muy, muy pequeño. Pero las artes marciales son algo que puede hacerse desde que se es un niño pequeño hasta cuando tengas ochenta o noventa años. Mi abuelo es testigo de esto. Animo a las madres y a los padres a que se suscriban a las artes marciales porque conozco lo bueno que puede ser para ellos y para sus familias. Y pienso que es bueno para la sociedad. Simplemente hay tanta presión puesta en los niños con todo el fútbol, hockey, y baloncesto... tanta presión puesta en los deportes, que somos afortunados de que el taekwondo tenga una cara marcial y otra deportiva. El baloncesto no tiene ese enfoque de desarrollo saludable o de desarrollo integral de la persona. Es sólo un deporte.

JS: Quizá los deportes en niños deberían engranarse para desarrollar a la persona, mientras que el desarrollo de un atleta profesional es diferente.

JMM: Sí, es otra situación diferente. Estoy seguro de que puede ser discutida, que habrá algunas personas que digan, "no", los niños necesitan empezar pronto si quieren tener éxito y estar en la cima. Pero yo creo que, A) la vida es demasiado corta, y B) los niños son niños. Necesitan jugar, divertirse, ensuciarse, cometer errores, y no ser reprendidos, castigados o despreciados por esas cosas. Eso se ha perdido un poco debido a que todo es tan rápido y lo necesitamos ahora, y tenemos que ser buenos ahora, y tenemos que ser listos ahora. Los chicos deben ir al colegio a los dos años para que lleguen a ser doctores. Si va a pasar, pasará. ¿Podemos ayudarles a adelantar su desarrollo? Seguro. Quiero decir, todo el mundo quiere las mejores cosas para sus niños. Pero a veces querer tanto y tan rápido puede romper la esencia de ser, simplemente, un niño.

JS: He estado en su gimnasio y he conocido a sus atletas. Ellos son educados y humildes y parecen ser rectos en términos del carácter, como en algunas escuelas de artes marciales en las que también he estado. ¿Esto es debido a que es un deporte marcial, o si me encontrara cualquier equipo deportivo de alto nivel me encontraría con una cortesía y un carácter similar?

JMM: Realmente no, tiene razón. Es debido a que es un deporte marcial. Yo he usado esa palabra antes como un tipo de híbrido entre arte marcial y deporte. Así que deporte marcial es un término muy bueno. Primero, mis atletas tienen antecedentes en las artes marciales, y por ello entienden la disciplina y el respeto. Y entonces yo, que soy la persona que soy, me aseguro de que eso continúe. ¿Nos divertimos? ¿Derribamos algunas barreras? Sí.

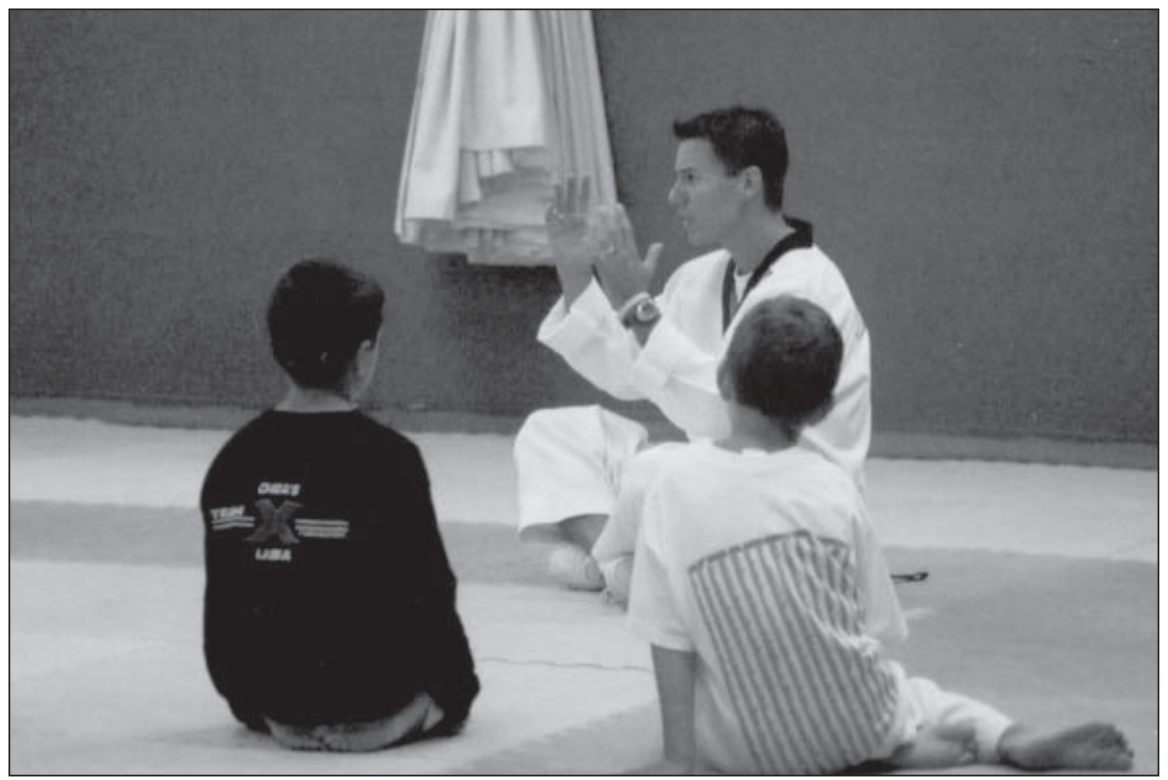

Los consejos y entusiasmo de Moreno capturan fácilmente la atención de los más jóvenes. 
Moreno enseñando el estilo olímpico de taekwondo con un toque de filosofía oriental y occidental.

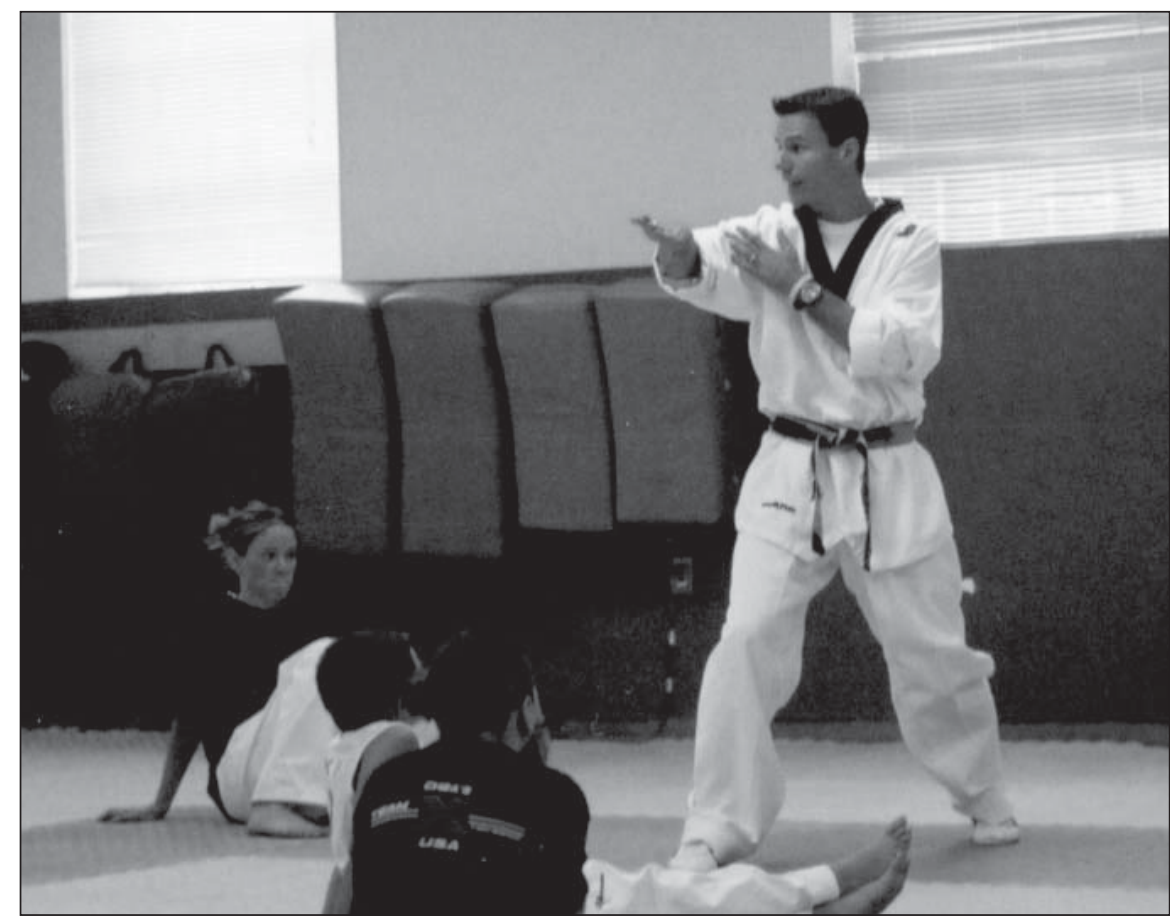

Pero nosotros todavía tenemos una tonelada de respeto. Nuestra meta es ser deportistas, pero también ser buenas personas.

\section{JS: ¿Ve esto en otros equipos de taekwondo?}

JMM: Creo que no. Probablemente usted lo verá en la mayoría de ellos, pero hay una posibilidad real y temible donde el taekwondo podría volverse como el judo deportivo, ya que en los EE.UU. el judo es un deporte. Hay muy poco arte marcial en todo. Ellos realmente han perdido algunas de sus tradiciones que eran realmente la fibra, la médula espinal, algunas de esas cosas buenas. Mire a algunos de los equipos de taekwondo, también lo están perdiendo. Están intentando hacerlo tan occidental que, de nuevo, quizá estoy contradiciéndome un poco, porque me gusta el acercamiento occidental y el deporte occidental. Pero pienso que hay algunas cosas buenas en la filosofía asiática.

JS: Quizás sea un problema de equilibrio.

JMM: Sí, definitivamente hay una cuestión de equilibrio. Para contestar a su pregunta, podrá ver algunos equipos fuera de aquí que no son muy respetuosos, no son muy humildes, que no están conducidos socialmente, que no cuidan el ser parte de la familia del taekwondo y ayudar al desarrollo de todos.

JS: Parece ser que algunas personas que provienen de otras artes marciales y se adaptan al taekwondo olímpico y lo hacen bien, como Arlene Lima (de Chicago, miembro del equipo americano en 1988 y medallista de oro olímpica).

JMM: Sí

JS: ¿Ve eso en países como Japón y China, donde la gente pueden venir de artes marciales tradicionales como el kárate y el gong fu y pueden seguir en los equipos olímpicos de taekwondo y hacerlo bien?

JMM: El hecho es que en los Estados Unidos todos tienen antecedentes en las artes marciales. Es discutible cuánto tienen de tradicional. Pero usted no escoge a un chico de la calle y le enseña cómo hacer taekwondo deportivo como puede hacerse en baloncesto, béisbol o fútbol. Pero en otros países es 
al contrario. Ellos están consiguiendo atletas. Encuentran atletas en China que pasan de ser anteriormente jugadores de voleibol, saltadores de altura, o velocistas.

JS: ¿Ellos no están utilizando a sus artistas marciales, pero utilizan a sus atletas en otros deportes?

JMM: Ellos pueden usar a algunos artistas marciales, pero hablando en términos generales, no. Están encontrando personas atléticas. Es lo mismo que en los antiguos países del este. Como, por ejemplo, Azerbaiyán. Este país me viene a la cabeza porque en el Campeonato del Mundo de 1999, tenían un equipo pequeño. ¡Y en 2001 tenían un campeón mundial! Este tipo no había practicado taekwondo tradicional o taekwondo deportivo durante mucho tiempo. Lo que ellos están haciendo es encontrar atletas, usando la línea de desarrollo atlético, no de desarrollo del taekwondo, para hacer atletas buenos y fuertes, mental y físicamente. Y entonces les enseñan taekwondo.

Así que vamos a tener que recortar nuestro trabajo, porque estos tipos están sacando atletas más rápidamente. Y también pueden terminar más rápidamente. Quiero decir, que están ahí durante tres o cuatro años. Y justo cuando piensas que ya los conoces se libran de ellos trayendo a alguien nuevo que, probablemente, sea mejor que el anterior.

JS: Es un tema para investigar. Si se tomara un grupo de niños con talento para las artes marciales y a un grupo de atletas talentosos y se les enseñase taekwondo, ver qué grupo es mejor.

JMM: Creo que sería interesante. Vuelvo a lo que dije. Pienso que el factor subyacente puede ser la estructura mental de las artes marciales tradicionales. Siendo fuerte, de nuevo, pensando sobre el proceso en lugar de pensar sobre el resultado. Pero entonces, por otro lado, el lado físico, el atleta que ha entrenando con pesas, y ha corrido, y todo ese tipo de material. Así que podía ser un estudio interesante.

JS: Usted ha viajado realmente bastante por competiciones internacionales y ha entrenado mucho en Corea. ¿Esta distinción entre el entrenamiento de las artes marciales tradicionales y el entrenamiento de atletas es menos pertinente en países asiáticos, o es esta es una preocupación occidental?

JMM: Obviamente el taekwondo es de Corea, y todos tenemos esa visión de que el taekwondo es muy tradicional en Corea. Y no es así, no durante los últimos treinta años. Antes de eso, el taekwondo deportivo no estaba por todas partes. Lo que se practicaba se llamó taekwondo, pero realmente era kárate japonés. Tengo un amigo con un doctorado en historia que enseña en Corea. Él señala que lo que se ve ahora en Corea es el taekwondo coreano "tradicional", y el taekwondo que vino antes era kárate japonés. Cuando los japoneses ocuparon Corea se lo enseñaron a los coreanos. Los coreanos lo practicaron, le cambiaron el nombre y le dieron un giro un poco diferente. Pero el taekwondo moderno es el taekwondo coreano, con sus formas de desplazarse y amagar, de dar patadas y moverse en lugar de bloquear, con posiciones altas en lugar de posiciones bajas y estables. En lugar de los ataques tradicionales, la defensa, el contraataque, o ataque, bloqueo, y contraataque, cambiaron a atacar, evadir, y contraatacar, para no ser golpeados. Ellos lo hicieron inicialmente debido a sus parámetros corporales, ya que no eran los tipos más grandes y más fuertes. Así que no querían recibir el impacto de un ataque realizado por una persona más grande. Desde que vino el taekwondo deportivo ha estado en las escuelas de formación básica, en las escuelas secundarias, en la universidad, en los profesionales, y en los equipos del ejército. Y le digo que cuando están en la escuela básica no están practicando el bloqueo bajo y no están aprendiendo las formas. No están aprendiendo cómo dar patadas de arriba a abajo en el gimnasio. Están aprendiendo a combatir. Están aprendiendo a desenvolverse en situaciones 


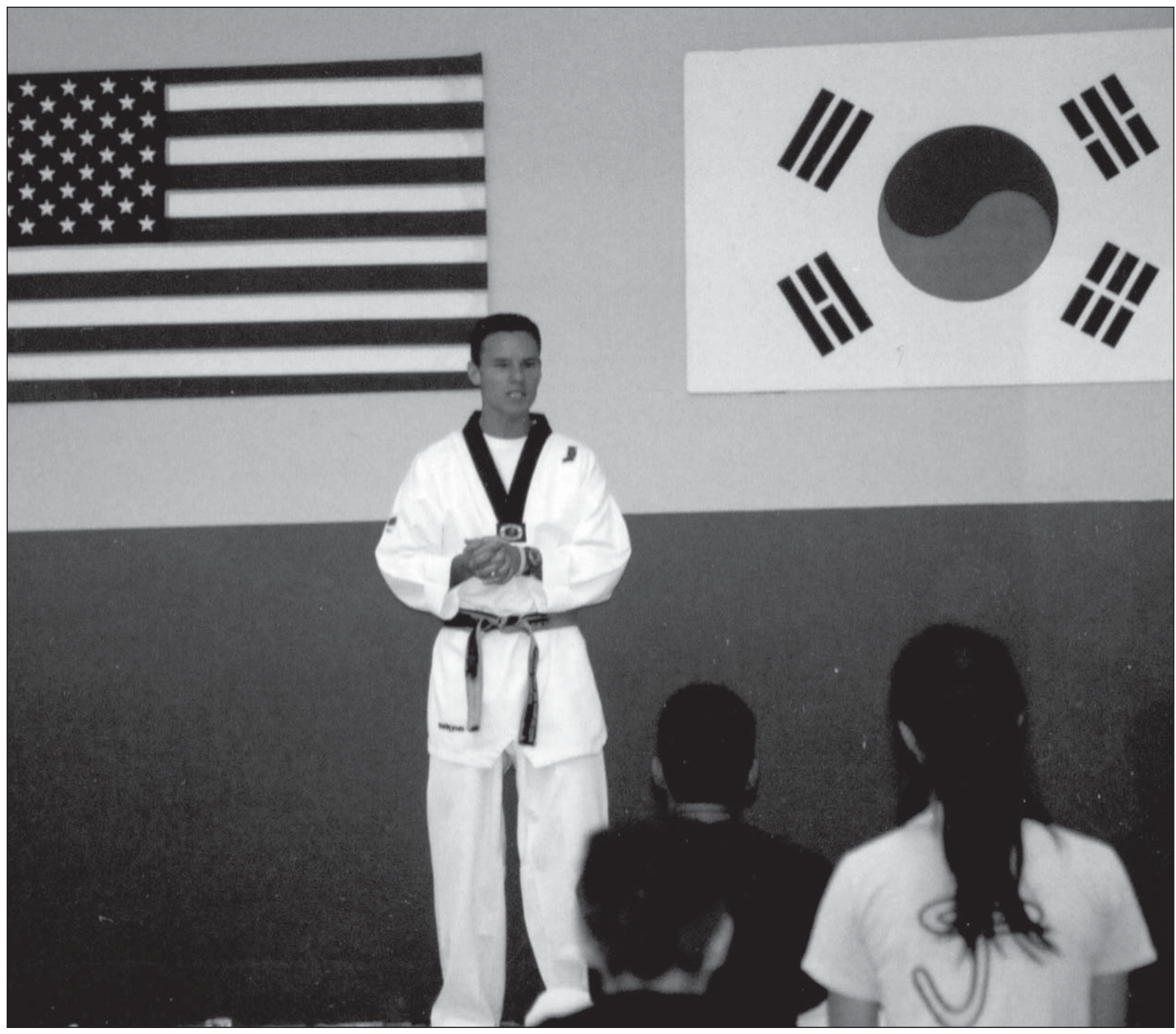

Con las banderas de Estados Unidos y Corea a su espalda, Moreno encarna el desarrollo moderno del taekwondo y sus perspectivas de futuro. o haciendo ejercicios de situación. Ese es el taekwondo tradicional coreano, a pesar del hecho de que el taekwondo deportivo es joven. Así que para contestar la pregunta, pienso que Corea es hoy día mucho más progresista. Las personas que lo practican no son tan tradicionales. Y creo que esto es aún más corriente en el resto del mundo asiático, ya sean las Filipinas o el Taipei chino. Ellos practican el taekwondo desde la perspectiva deportiva.

JS: Me pregunto si habrá algunos países asiáticos con artes marciales como el kickboxing tailandés o el sumo que sean realizados de forma competitiva, pero donde la pregunta de si eres un artista marcial o un atleta no es tan relevante. JMM: Sabe qué pienso, que no es relevante. Y le diré por qué. Pienso que sólo es porque el taekwondo es un deporte olímpico. Eso es lo que lo separa de todas esas otras cosas. Es por eso por lo que antes me hizo la pregunta de: “¿Cuándo se vio usted como un atleta?". Recuerde, yo ni siquiera sabía sobre la competición en los Juegos Olímpicos. El taekwondo no era olímpico cuando comencé a practicarlo. Sencillamente me consideraba bueno en kárate. Era bueno cuando iba a torneos de kárate y ganaba. Y nunca lo vi como un deporte, como un deporte de escuela secundaria. Sólo les decía a mis amigos, 
"vosotros no entendéis lo que hago. Voy a los torneos y lucho contra otros artistas marciales". Los kickboxers tailandeses se preocupan por su arte y por su deporte. Ellos entrenan una cierta manera de luchar usando su estilo de combate. Y podría pensar que el sanshou (el estilo libre de combate chino) y artes marciales de este tipo, probablemente también estén en esta esfera. ¡Pero si alguna vez consiguieran un nivel olímpico cambiarían, la dinámica de su deporte cambiaría! La tradición saldría por la ventana, porque la única cosa que importa en un deporte olímpico, cuando realmente te dedicas a ello, sin intentar ser moral, es conseguir ser más fuerte, más rápido, más inteligente. Porque es lo que va a ayudarte a ganar. Mientras que si eres moral o éticamente correcto no afecta a si vas a ganar o no. Realmente no afecta. La velocidad, la fuerza, la inteligencia, esos son los atributos que realmente te ayudan a ganan la competición.

JS: Esto es probablemente hacerle de nuevo la misma pregunta, pero ila distinción entre las artistas marciales y los atletas es igualmente aplicable a los deportes marciales como el judo, o es único en el taekwondo?

JMM: Yo pienso que es aplicable. Eche una mirada al judo alrededor del mundo. Hay todavía algunos maestros del judo que solamente trabajan y entrenan a gente de forma tradicional. Pero mira países como Irán, Grecia o Francia. Son practicantes del judo deportivo. El tema, de hecho, es que los atletas de judo en Europa son estrellas. Son estrellas reconocibles. Son como el fútbol, el baloncesto, las estrellas de fútbol americano. ¿Y proceden de una escuela tradicional? Sí. Pero entrenan con un propósito, ganar competiciones. Es ganar medallas y medallas de oro para su país. Así que pienso que es aplicable. Se mueven, por así decirlo, en una filosofía con orientación deportiva. No es para cada arte marcial, pero sí para, yo diría, probablemente el taekwondo, el judo, y hoy en día un poco, el jujutsu, sabe, la lucha cuerpo a cuerpo. Obviamente está el K1 y el no-holds-barred, que no son prácticas olímpicas, pero esos tipos lo son, son artistas marciales, pero en mayor medida son atletas.

\section{Conclusión}

Esta entrevista muestra cómo un atleta marcial de clase mundial ve la diferencia entre llegar a ser un artista marcial y llegar a ser atleta en un deporte marcial. También deducimos alguna idea de lo que subyace al gran éxito del Sr. Moreno como atleta: su intensidad en los objetivos, una marcha imparable hacia la perfección de la habilidad, una voluntad de sacrificio y una apertura hacia los nuevos métodos de entrenamiento físico y psicológico. Estos atributos mentales deben combinarse con la dotación genética de un cierto tipo del cuerpo y velocidad para que se produzca un atleta único como el Sr. Moreno, en cualquier deporte.

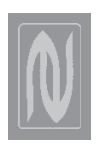

\section{Agradecimiento}

